\title{
An Evaluation of Career Transition Phenomenon
}

\author{
Adelé Janse van Rensburg \\ Wilfred I. Ukpere \\ Department of Industrial Psychology and People Management, \\ Faculty of Management, University of Johannesburg, Johannesburg, South Africa
}

\section{Doi:10.5901/mjss.2014.v5n1p725}

E-mail: wiukpere@uj.ac.za

\begin{abstract}
The purpose of the study was to develop a substantive grounded theory on the inter-profession career transition phenomenon as experienced by eight transitioning individuals. With an interpretive qualitative approach, data was collected through memoirs, interviews and literature. The Straussarian data analysis entailed open coding, axial coding, and selective coding. Each new participant analysed was chosen following the theoretical sampling technique. The qualitative data analysis software programme called ATLAS.ti was utilized to store all the data collected. Five categories were identified through the analysis process and include: (1) Triggers for change; (2) Decision making; (3) Job seeking; (4) Preparations; and (5) Coping strategies. Through selective coding a core category was developed which stated: Personal preferences as a set of interrelated beliefs do not only influence but also lead the career transition of professionals from beginning to end. Future research is recommended to explore other types of career transition as well as the various similarities and differences identified between the participants.
\end{abstract}

Keywords, Career transition, grounded theory, personal preference, professional, career types, contemporary careers

\section{Introduction}

How do certain individuals just change jobs, seemingly successfully, whilst others stay stuck in their career forever? Moreover, how do these individuals change career paths, for example, a preacher becomes an information technology expert or a teacher becomes a dancer? This paper is directed to provide answers to the career transition phenomenon.

Considering the evolving nature of careers, it is necessary to follow the changes in the definitions for career from the traditional to the more conventional. It became evident through examining the different definitions, that time and a changing work environment played a major role in reshaping the definitions to what they are today. Career is defined as a "set of events, activities, experiences, and decisions that occur over the course of an individual's work life" (Louis, 1982: 69). Noticeably, this definition includes periods where individuals are within a job as well as for jobless periods and it encapsulates not only the job itself but also the experiences and the circumstances surrounding the job state. Transition is defined as "an event or non-event [that] results in a change in assumptions about oneself and the world and thus requires a corresponding change in one's behavior and relationships" (Schlossberg, 1981:5). Transitioning entails both the individual background as well as the relationships between the individual and various other life roles as it has a long-standing impact on the individual (Teixeira \& Gomes, 2000). Career transition can be defined as "the period during which an individual is either changing roles (taking on a different objective role) or changing orientation to a role already held (altering a subjective state)" (Louis, 1980:330).

Traditionally careers were associated with single employment in one company with a steady upwards progression. This upward progression presupposed a vertical movement up the corporate ladder in search of external elements such as higher income and promotion up the hierarchy (Brousseau, Driver, Eneroth, \& Larsson, 1993; Foot \& Vene, 1990; Kelly, Brannick, Hulpke, Levine, \& To, 2003). These traditional careers were described as linear careers (Foot \& Vene, 1990; Lichtenstein \& Mendenhall, 2002; Woodd, 2000) with a direct correlation between an employee's age and the associated level in the hierarchy (Foot \& Vene, 1990). The term career was applicable to a selected few as it referred only to professional and higher occupations and was equated to "advanced levels of education" (Schein, 1984:72). Then came elements such as "reorganizing, downsizing, rightsizing, delayering, flattening the pyramid, teaming and outsourcing" (Brousseau, Driver, Eneroth, \& Larsson, 1993:52) and caused mayhem to the traditional view and knowledge on careers. Due to these change elements, a whole new world in terms of careers emerged. The career concept became more neutral and applicable to all occupations (Schein, 1984) as new descriptive phrases were 
developed such as steady state, spiral, protean, boundary and transitory careers. With all these new existing career phrases, career transitioning ${ }^{1}$ no longer just referred to entering and exiting work but included a whole range of upward, downward, spiral and horizontal movements.

The full spectrum of inter-profession career transitions "including past experiences, ... present circumstances, ... and future prospects" of individuals should be under study (Moen, 2005:190). The importance of investigating individuals' experiences is highlighted by Carless and Douglas (2009:52) who stated that "the ways career transition affects an individual is best understood in light of earlier events in her or his life, the personal meaning of [career]..., and the potential impact of co-occurring transitions".

\section{Research problem and questions}

No integrated, end-to-end view on the career transition phenomenon, which describes the how; what; when and why of inter-profession career transition from the view-point of the transitioning individual, existed previously.

In light of the above research problem, the following research questions were developed to provide direction without predicting the outcome (Wilig, 2001):

- Why do individuals embark on career transition and what triggers or inhibits a transition?

- How do individuals transition successfully from one career to another and how do other life roles influence their decisions?

- How do organisations assist career transitioners and do they understand and assist the transitioners?

- $\quad$ Are certain individuals more receptive to transitioning than others?

- How do individuals make sense of the transition?

\section{Research Objectives}

The objectives of the study are as follows:

- $\quad$ To indicate current trends and definitions from existing literature;

- To explain the phenomenon of career transition from the perspective of individuals who have made interprofessional transitions;

- To reach an understanding of the process of career transition including all other aspects which may or may not influence the transition in order to manage one's own career; and

- $\quad$ To provide guidelines to those who manage and work with career transitioning individuals.

\section{Research Methodology}

Within this qualitative process, a combination of interpretivism and constructivism were applied for this study as both is concerned with "understanding phenomena from within their context" (Terre Blanche \& Durrheim, 1999:399). Although the two philosophies are not the same, some researchers have combined these two philosophies under interpretivism (Saunders, Lewis, \& Thornhill, 2003; Terre Blanche \& Durrheim, 1999; Locke, 2001) since they share some common elements. In addition, an abductive approach (Bryant \& Charmaz, 2007) was followed which consists of both an inductive and deductive approach. Broadly, the end state of a deductive approach is the confirmation or verification of a theory or hypothesis whereas with an inductive approach the end state is the development of a theory (Thorne, 2000). "Abduction inference entails considering all possible theoretical explanations for the data, forming hypothesis for each possible explanation, checking them empirically by examining data, and pursuing the most plausible explanation" (Charmaz, 2006:188), which is based on grounded theory.

\section{Grounded Theory}

Grounded theory (hereafter referred to as GT) is a well-known research method with an "accommodating nature" and a predisposition to provide "flexible guidelines" and a set of "principles and practices" rather than "prescriptions or packages" (Charmaz, 2006:2, 9). The specific term Grounded Theory was chosen to indicate that theory is generated from or grounded in the data (Pidgeon \& Henwood, 1997). The grounded theorist are not concerned with testing prior

\footnotetext{
1 The terms career movements and career transition will be used interchangeably throughout this document
} 
theories, but rather with how participants view reality themselves (LaRossa, 2005; Locke, 2001). Chiovitti (2003) observed that there is more than one version of GT to be applied. The Glaserian School represented an orderly process for conceptualisation (Glaser, 2002) whilst the Straussarian School stressed complex coding techniques (Goulding, 1999). The techniques of Corbin and Strauss (Strausarian school of thought) were applied as it provides a systematic coding technique which is relatively easy to follow and replicate. Besides theory building being the major purpose of GT, it also allows the researcher to "explicate what is going on or what is happening (or has happened) within a setting or around a particular event" (Morse, Stern, Corbin, Bowers, Charmaz, \& Clarke, 2009, p. 14).

\section{Data Collection}

The iterative process "merges the process of data collection and analysis" (Willig, 2008:27) in order to enable the development of theory which is grounded in the data (Willig, 2008). Data was collected through sampling processes where firstly the most obvious cases were identified through convenience sampling. Purposeful sampling assisted in directing the emerging theory based on the developing categories. Lastly, through theoretical sampling the sampling became more selective as it focussed on categories essential to the emerging theory. Glaser and Strauss (1967:45) define theoretical sampling as "the process of data collection for generating theory whereby the analyst jointly collects, codes and analyses his data and decides what data to collect next and where to find them, in order to develop his theory as it emerges". The three data collection methods utilised for this study were participant memoirs, individual interviews and existing literature. A qualitative data analysis (QDA) program called Atlas.ti was used to assist with data management in the form of storage, ordering and easy retrieval (Atherton \& Elsmore, 2007; Rettie, Robinson, Radke, \& Ye, 2008).

\section{Data Analysis}

The data analysed were in the form of memoirs submitted by the participants, interviews and literature. The memoir, interview and any other relevant data pertaining to the analysis were analysed and broad concepts identified prior to conducting theoretical sampling for the next concept. Mind maps were created as part of the analysis. During the mind mapping exercise, related codes were grouped together. The grouping of similar codes is called a concept (Allan, 2003). Concepts are "words that stand for ideas contained in data. In other words, concepts are specific labels given to describe a specific piece of data. As the axial coding happened without a conscious effort, the first two steps namely open coding and axial coding was done simultaneously.

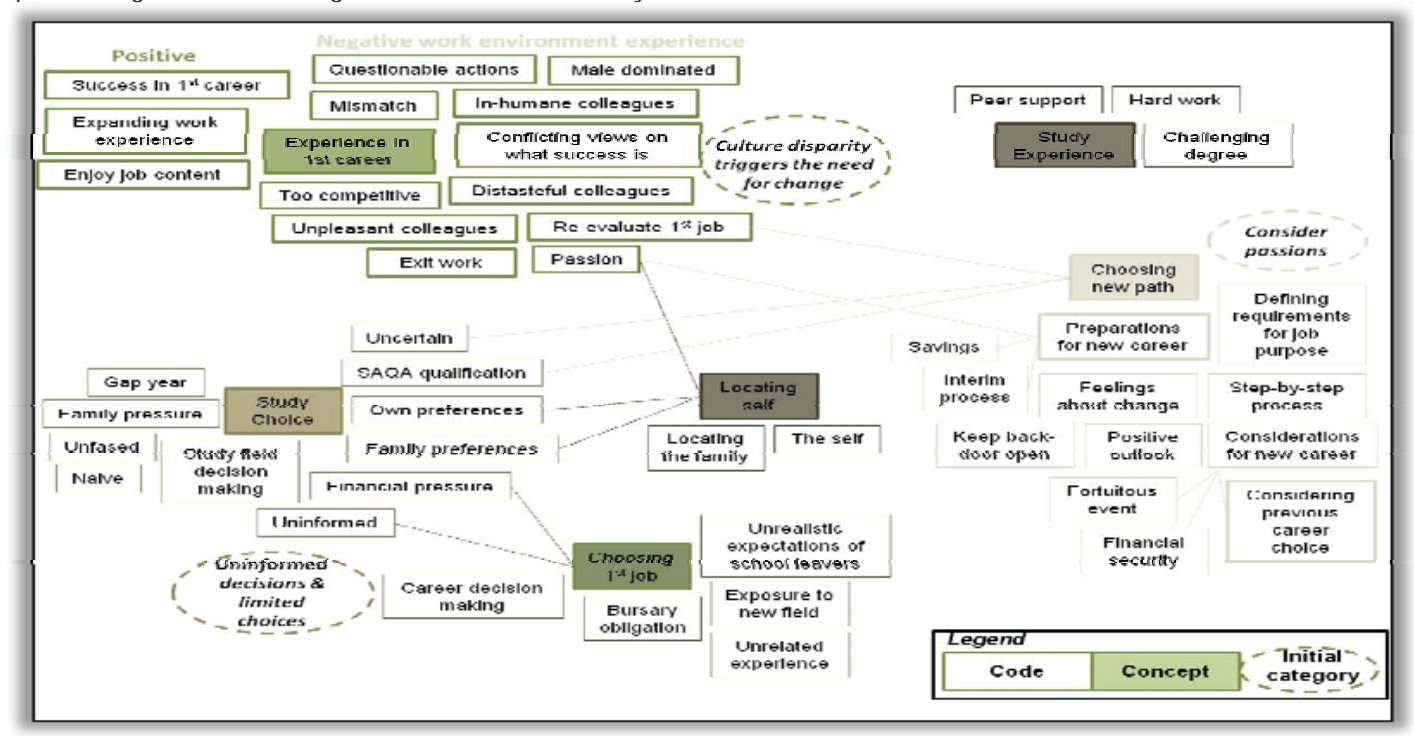

Figure 1: Mind map of open coding process

Source: Authors' fieldwork 
Figure 1 above provides an overview of the three initial themes or categories identified from the first case. As we interpreted the data, these three categories were of central importance to the evolving storyline. The next case study has built on this analysis. In other words, we were interested to understand what differences or similarities exist between individuals based on the above three initial categories. In addition to coding for these three categories, it was also imperative to keep the original problem statement in mind. Therefore, with the second case, we did not only code for (1) triggers for transition, (2) decision making, and (3) scoping for an ideal career, but also (4) to unveil any data on how the individuals experienced their career transition, (5) how the transitions were facilitated, and (6) how they made a success of the change. The next cases (participants) chosen from here on were random choices from the participant database since all of them referred to or mentioned elements that might enhance the categories already identified. The focus was just to work through all the remaining memoirs and to identify as many new categories as possible and elaborate on the already identified ones.

The same process was followed with the rest of the case studies. The memoirs were coded section by section looking for similarities and differences to the concepts identified in the previous case studies. Similar concepts were coded by using the same code name, although the purpose with each new case was to seek out new properties to further explain the concept. Properties are those elements that adequately describe the specific concept. Each new case was analysed to fill the already identified theoretical categories and to extend the emerging theory (Yin, 1989 as cited in Pandit, 1996). In other words, the question of 'what else can be learnt about this concept' was asked if the same concept was identified. The constant comparative method was applied by "comparing like for like, to look for emerging patterns and themes" (Goulding, 1999:9). Throughout the process, our thoughts and interpretation of what the data portrayed were captured in memos. Any new insights were added to the list of properties for that specific concept whilst new concepts were added to the list of codes. The initial three categories were either "verified, invalidated or amended" depending on what was found in the following memoirs (Corbin \& Strauss, 2008, p. 199). The naming of the initial three categories was amended slightly to be more descriptive as new concepts and properties were added. Table 1 provides an overview of how the codes, concepts and categories evolved over time.

Table 1: Overview of Evolving Categories

\begin{tabular}{|c|c|c|c|}
\hline Concepts & $1^{\text {st }}$ Categories & Revised Categories & Initial Categories \\
\hline $\begin{array}{l}\text { - Experience in first career } \\
\text { - Study choice } \\
\text { - Choosing first job } \\
\text { - Choosing a new path }\end{array}$ & $\begin{array}{l}\text { - Culture disparity triggers } \\
\text { the need for change } \\
\text { - Uninformed decisions } \\
\text { and limited choices } \\
\text { - Consider passion }\end{array}$ & $\begin{array}{l}\text { - Triggers for career } \\
\text { transition } \\
\text { - Decision making } \\
\text { - Scoping an ideal career } \\
\text { - Coping strategies } \\
\text { - Preparations for new } \\
\text { career } \\
\text { - Reflections on change }\end{array}$ & $\begin{array}{l}\text { - } \text { Triggers for career } \\
\text { transition } \\
\text { - Decision making } \\
\text { - Scoping an ideal career } \\
\text { - Coping strategies } \\
\text { - Preparations for new } \\
\text { career } \\
\text { - Reflections on change } \\
\text { - Barriers } \\
\text { - Job seeking strategies }\end{array}$ \\
\hline
\end{tabular}

Source: Authors' fieldwork

Axial coding was the process where sub-categories were linked to broader categories but also where relationships were identified between the different categories. The concepts needed to answer the questions of "what, how, when, where, and why" (Corbin \& Strauss, 2008:55). Therefore, based on the initial categories, the participants were interviewed to further explore the relationships between the categories. Unfortunately, due to time constraints, geographical difficulties and constantly changing diaries, face-to-face interviews were not possible. As an alternative method, a series of questions were developed to explore the various relationships between the categories and e-mailed to the participants. The interview questions were specifically designed to extract additional information on some generalisations that we have made about the data.

After coding the fifth memoir, a sense of déjà vu emerged as the same codes and concepts kept re-emerging. This is called theoretical saturation. Theoretical saturation occurs when additional coding add little new to the already developed categories (Corbin \& Strauss, 2008; Burden \& Roodt, 2007). However, a decision was made to continue coding the final three memoirs just to ensure that all areas are covered adequately. Also, since this was an incipient 
attempt at GT, there was always this constant need to double check. Therefore, the remainder of the memoirs were coded looking specifically for new concepts. Although the categories became more descriptive and some additional differences were identified with the last three memoirs, no new concepts were identified. This confirmed the theoretical saturation stage which ended with eight initial categories.

At this stage, the mind map was very dense and spanned across a couple of excel sheets. Due to the large volume of information, it is not possible to portray all the detail of the mind map in this document. However, Figure 2 provides an overview of the analysis as it progressed, including data from memos, concepts, initial categories and interview questionnaires. Figure 2 also clearly indicates the various relationships identified between the categories and concepts as derived from the data. It should also be noted that the original eight categories were now re-grouped into five main categories: 1) Triggers for Change, 2) Decision Making, 3) Job Seeking, 4) Preparations, and 5) Coping Strategies.

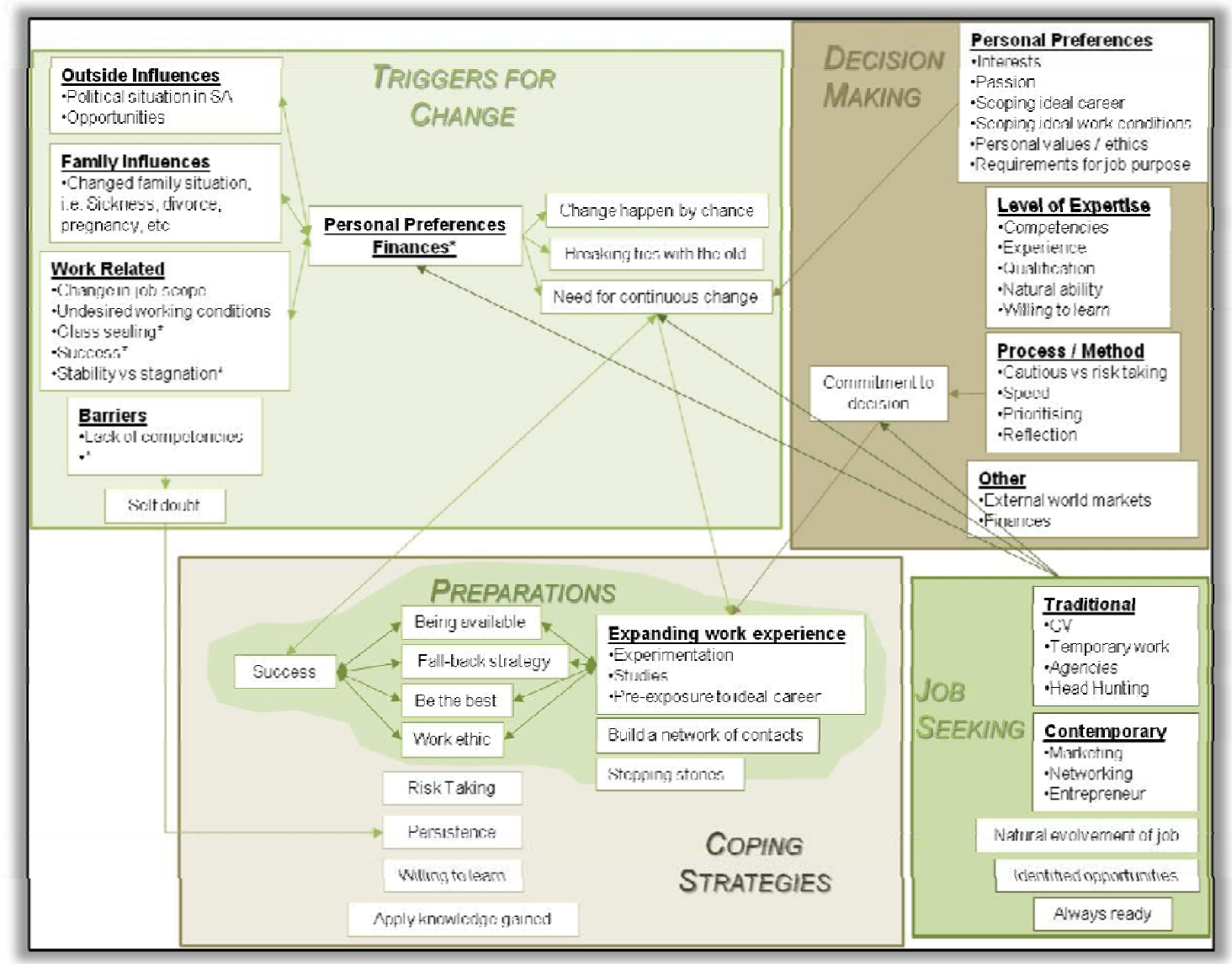

Figure 2: Bird's Eye View of Axial Coding Source: Authors' fieldwork

In addition to the above memoirs and interview answers pertaining to career transitions, it was felt important to also theoretically sample for non-transitioners. The reason for sampling non-transitioners was to include data "that is polar opposite to extend the emerging theory" (Yin, 1989, pp. 53-54). A "negative case" will assist in providing an "alternative explanation" and a "fuller exploration" (Corbin \& Strauss, 2008, p. 84). Therefore, data on non-transitioners were analysed to ascertain if non-transitioning were as a result of the absence of the initial categories already identified. Rather than going through the whole sourcing for participants process again, purposive sampling was done to obtain relevant literature on non-transitioners. The coding process focussed again on the emerging categories, but this time to find the opposite of the already identified properties. An article by Ibarra (2002) called 'How to Stay Stuck in the Wrong 
Career' which focussed on reasons for not transitioning was chosen and subsequently coded. The reasons for nontransitioning identified by the said author confirmed the evolving theme as all of the reasons for not transitioning was absent from the memoirs of the transitioned participants for this study.

Selective coding was the last phase of coding. It "pertains to coding systematically and concertedly for the core category" as this core code became the "guide to further theoretical sampling and data collection" (Saunders, Lewis, \& Thornhill, 2003:33). A core category is a combination of all information in order to provide an explanation of the behaviour under study. The core category again is very much dependent on the perspective of the researcher and where the researcher wants to place the emphasis (Corbin \& Strauss, 2008). It is very important to note that having been immersed in the data for some time; the core category did not just appear from the data. It took time, distance from the data, numerous re-reading of the data (in particular the memos) and also an element of gut feeling. The mind maps were essential to selecting a core category. In essence, stories about the various mind maps were written again and again until it finally made sense and came together to provide an integrative view of the career transition phenomenon. After the 'testing' and confirmation of the core category, the following phrase was developed to describe the core category:

\section{Personal preferences as a set of interrelated beliefs and passions not only influence but also lead the career transition of professionals from beginning to end.}

Again be reminded that the choosing of a core category was our choice as adequately described by Corbin and Strauss (2008, p. 266): "The core concept and other concepts come from the data but 'theory' doesn't just build itself; in the end, it is a construction build by the analyst from data provided by participants". To evolve the storyline, relevant literature was incorporated.

\section{Literature review}

There seems to be a huge debate over whether or not a literature review should be included in a GT study. In addition, those who believe that a literature review should be included cannot seem to agree on when to conduct this review. Table 2 provides an overview of some of the existing opinions ranging from views between the creation of the original GT to the more recent and contemporary views on the place of literature in GT.

\section{Table 2: Literature Review in GT}

Arguments AGAINST a Literature Review

- "The first step in gaining theoretical sensitivity is to enter the research setting with as few predetermined ideas as possible" (Glaser, 1978:3).

- Some researchers believe that literature should be avoided at all cost as to not "contaminate their coding" (LaRossa, 2005:850).

- "There is a need not to review any of the literature in the substantive area under study" (Glaser, 1992:31).

- "Grounded theory must be free from the idea of working on someone else's product" (Reetley, 2008:37).

\section{Arguments FOR a Literature Review}

- "Acknowledge the value of reviewing prior research" (LaRossa, 2005, p. 250).

- Inclusion of literature adds another voice to the one of the researcher (Mills, Bonner, \& Francis, 2006).

- Pandit (1996) concluded that the final step is to include literature to ascertain similarities, differences and reasons thereof to one's study.

- "After data have been .... analysed, then the researcher may begin to review the literature in the substantive field and relate the literature to her/his own work" (Reetley, 2008, p. 37).

- "A common misperception is that grounded theory requires a researcher to enter the field without any knowledge of prior research" (Suddaby, 2006:634).

- "Careful analysis of relevant extant literatures after developing one's grounded theory can provide cues for raising its theoretical level" (Bryant \& Charmaz, 2007:20).

Following the above divergent views, LaRossa (2005:850) adequately concluded that "how prior work should be used is up to the individual researcher". In this instance, we firmly believe that literature is a big part of the emerging theory. This viewpoint is confirmed by Bowen (2005:210) who stated that:

The first lesson I learned was to read extensively and then read some more... After all, one needs to know what research exists and how others have treated a particular topic so one can determine what additional 
research is needed. Prior studies provide a foundation, background, and context for new research; it establishes a bridge between the (proposed) research project and the extant knowledge base.

A more in depth literature review was done as soon as the core category was developed. It is important to note that due to the concise length of a journal article, only an abbreviated version of the detailed literature review is discussed below.

\section{New Descriptive Career Phrases}

As periodic profession change became more prominent, new descriptive career phrases were developed such as protean, boundaryless, steady state, spiral, and transitory careers. Proteanism ${ }^{2}$ refers to "adaptive career transition making" (Bandow, Minsky, \& Voss, 2007, p. 28). In essence, it means that the individual is responsible for his or her own career rather than the company. The individuals' career is reinvented continuously in response to the changing world (Bridgstock, 2011; Hall, 1996) and success is defined based on "the degree of job satisfaction, self-actualisation, personal accomplishment and a feeling of fulfilment" (De Briun \& Buchner, 2010). Boundaryless careers are characterised by individuals moving from "job to job, or from organisation to organisation thus transcending physical boundaries" (Clarke, 2009:11). Spiral careers according to Brousseau et. al. (1996) consists of a series of movements within or outside of a current profession. Usually, individuals move to a new career every 7-10 years or as soon as they developed the competence needed for the current job. These skills are then applied from one job to another. Steadystate careers - also referred to as professionals or expert careers - refer to professionals as having a "lifelong commitment to some occupational field or speciality" (Brousseau, Driver, Eneroth, \& Larsson, 1996:56). These careerists desire "expertise or technical competence, security and stability" (El-Sabaa, 2001:3). The individuals acquire the requisite qualifications, training and experience to qualify as an expert and then remain in the specific occupation (Woodd, 2000) either within one company or more than one company (Louis, 1980).

Transitory careers are mainly characterised by non-careerists as these individuals generally see themselves as not having a career (Brousseau, Driver, Eneroth, \& Larsson, 1996). These individuals are usually clerical workers (Woodd, 2000) because their skills can be easily transferable from one job to a very " different or wholly unrelated" job (Brousseau, Driver, Eneroth, \& Larsson, 1996:57). The main driver for change is variety and independence (Brousseau, Driver, Eneroth, \& Larsson, 1996). Louis (1980) concluded that these new change-oriented career opportunities lead to the increase of individuals undertaking some form of career transition. The focus of this study was inter-profession career transition (Louis, 1980) or transitory career concept (Brousseau, Driver, Eneroth, \& Larsson, 1993). The transitory career concept can be defined as individuals moving "form one field or job to a very different or wholly unrelated field or job" (Brousseau, Driver, Eneroth, \& Larsson, 1996:57) as well as "the movement to a new occupation that is not part of a typical career progression" (Rhodes \& Doering, 1983:631).

\section{Types of Career Transitions}

The typology of career transitions from Louis (1980) seems to be central to any and all research on career transitions. It seems to be the most quoted and applied typology in terms of research on careers. Louis (1980) explains that career transition consists of two categories namely inter-role and intra-role. Inter-role refers to new and different roles and is more or less a linear process. However an individual enters or re-enters an organisation(s) and progresses on his/her career journey either through lateral, horizontal, spiral or professional movements. All of these end with an exit process. In contrast, intra-role refers to the orientation towards an existing role that is changing. Intra-role transition includes intrarole adjustment (change in response to experiences over time) and extra-role adjustment (adjustment to work role as a result of change in one's life role), role/career-stage transition (career cycle stages) and life-stage transition (human development stages) (Louis, 1980). It is clear that in studying the concept of career transitions, both inter-role as well as intra-role transitions need to be considered.

\section{A Wider Perspective on Careers}

These additional views include information on other aspects surrounding the career concept:

\footnotetext{
${ }^{2}$ The term was created by Hall (1996) as cited by (Bandow, Minsky, \& Voss, 2007). It refers to the characteristically adaptive Greek god of the sea, Proteus who could change his shape at will.
} 
Career is more than just a Job - The new meaning of career is now inter-linked with one's life journey as Baruch (2004:59) summed up: "Career is a major life constituency - it evolves around work, and work provides a sense of purpose, challenge, self-fulfilment, and, of course, income ... work is a source of identity, creativity, life challenge, as well as status and access to social networking". A job is not merely a "means of survival, but also a major way of expressing and developing oneself and a source of social recognition" (Mayrhofer, Meyer, Schiffinger, \& Schmidt, 2008:296).

On-line literature pertaining to career change is dominated by opinion based authors providing non-scientific career information. A majority of the articles seem to contain a couple of steps to ultimate career bliss, for example the 3 key components to any successful change (Bailey, 2003), seven steps to change a career (Ford, 2008), 11 steps in career transition (Frank, 1996), and How to change careers (Levchuck, 2009). In addition to on-line literature, more than 3000 self-help books on career management were published in the 1900's only (Carson \& Carson, 1997). Most of these literature pertain to how to change careers including related decisions which Doerr (1995:101) calls "the mechanics of looking for a job". Although these issues are very important, they seem to provide only superficial information to prospective career transitioners.

\section{Possible reasons for transition}

The transition process starts where an individual is either triggered by something happening or by the absence of something happening. This action and non-action or push-pull factor indicates the omnipresence of a trigger which consists of the "constant state of self and situation evaluation - never ending and at variable intensity" (Mihal, Sorce, \& Comte, 1984:97). The triggers for change are actually the reason or source of unhappiness or discomfort. It is important to note that the triggers do not create the change, it rather trigger the need to explore alternative options based on personal preferences (Ibarra, 2004).

\section{Personality-Job-Match}

As personality plays a major role in career transitions (Chudzikowski, et al., 2009), it is only logical to assume that the personality-job-match plays an equally important role in pursuing new careers (Donahue, 2006). Therefore, individual differences in personality, attitude, ability, identity, self-concept and emotions plays a role in the choices the individuals make about their career (Peel \& Inkson, 2008). John Holland developed a theory of personality-job-fit. This theory "is based on the notion of fit between an individual's personality characteristics and his or her occupational environment" (Robbins, 2001:101). According to this theory, six personality types exist and success and contentment in a job depends on how well the individual's personality fits the specific job requirements. According to Holland's theory, there are different personalities, different jobs, and the closer the match between the personality and the job; the happier the person is (Robbins, 2001).

\section{Cultural Impact on Career Transition}

Culture seems to play a big role in career transition (Chudzikowski, et al., 2009; Gerber, Wittekind, Grote, Conway, \& Guest, 2009). In fact, Schein (1984) stated that the specific viewpoint individuals have about their career depends on their culture. Gerber et. al. (2009) found that career concepts or phrases such as protean, boundaryless and portfolio careers cannot be generalised between different cultures. Factors like autocracy versus autonomy, centralisation versus decentralisation, self-managed versus centralised management and hierarchical structures seems to vary between cultures (Kelly, Brannick, Hulpke, Levine, \& To, 2003) and will thus impact decisions around career transitions. In addition, organisations in different cultures also structure their career paths and training and development practices differently (Kelly, Brannick, Hulpke, Levine, \& To, 2003).

\section{Possible Barriers to Career Transition}

A study done on eight women exploring why a barrier becomes a barrier (Murtagh, Lopes, \& Lyons, 2007) found that it is generally the viewpoint of the individual that makes the distinction between an insurmountable barrier and one that can be overcome. Insurmountable barriers were defined as those that "prevented the individual from achieving wants, needs or values of personal salience" (Murtagh, Lopes, \& Lyons, 2007:336). However, in contrast, McDonald, Brown and Bradley (2005:118) found that no barrier is insurmountable, "because if the individual was determined enough, they could overcome anything". It was also found that "what could have been construed as a barrier instead seemed to serve as a trigger for change" (Murtagh, Lopes, \& Lyons, 2007:335). The question then is when is a barrier a barrier? The answer to this lies in a person's self-concept - what they think about themselves and how they want to be (Murtagh, Lopes, \& Lyons, 2007). 


\section{Career Anchors}

The concept of career anchors is important to this study as it reflects on what individuals consider when they are faced with a career decision (Schein, 1996). A career anchor is an individual's "self-concept, consisting of (1) self-perceived talents and abilities; (2) basic values, and most important; (3) the evolved sense of motives and needs as they pertain to the career" (Schein, 1996, p. 80). Nine career anchors have been identified of which the first five were the original classification as identified by Schein (1996, p. 80), the next three were identified later also by Schein (1996:80), whilst the last one was added by Suutari and Taka (2004:836): (1) Technical / functional competence; (2) Managerial competence; (3) Security and stability; (4) Autonomy and independence; (5) Entrepreneurial creativity; (6) Service and dedication to a cause; (7) Pure challenge; (8) Lifestyle; and (9) Internationalism.

\section{Findings}

Following the literature review, it became necessary to link the literature with the outcome of the study's data analysis. Table 3 below indicates where literature supported or enhanced the developing theory around career transitions. Each of the identified five categories, with its related sub-categories, were researched and presented in Table 3 below. Thereafter, additional insight from the literature, as well as from those who did not support the outcome of my studies, is discussed.

\section{Table 3: Overview of literature Findings}

\begin{tabular}{|c|c|c|}
\hline Category & Sub-categories & Findings in Literature \\
\hline \multirow[t]{3}{*}{ Triggers for change } & External influencers & $\begin{array}{l}\text { Enhanced: Change between companies is influenced by "networks high in external } \\
\text { relationships" (Ibarra, 2004:7). } \\
\text { Enhanced: "work-family relations are central to individuals ...they relate to issues } \\
\text { such as ... work-life balance, or career success" (Mayrhofer, Meyer, Schiffinger, \& } \\
\text { Schmidt, 2008:292). } \\
\text { Supported: "parents to be highly influential in their children's vocational development" } \\
\text { (Sargent \& Domberger, 2007:547). } \\
\text { Supported: "Careers ... are influenced by political, economic, historical and social- } \\
\text { cultural developments in society" (Dries, Pepermans, \& De Kerpel, 2008:907) }\end{array}$ \\
\hline & $\begin{array}{l}\text { Organisational } \\
\text { environment }\end{array}$ & $\begin{array}{l}\text { Supported: "Career perspective offered by the organization appears to have a } \\
\text { significant impact on employee outcomes like commitment, satisfaction and intention } \\
\text { to stay" (De Vos, Dewettinck, \& Buyens, 2008:159) }\end{array}$ \\
\hline & Barriers & $\begin{array}{l}\text { Supported: Structural barriers such as finances and education (Murtagh, Lopes, \& } \\
\text { Lyons, 2007) } \\
\text { Supported: Psychological barriers such as self-doubt (Murtagh, Lopes, \& Lyons, } \\
\text { 2007) } \\
\text { Enhanced: No barrier is a barrier, where there's a will, there's a way (McDonald, } \\
\text { Brown, \& Bradley, 2005) }\end{array}$ \\
\hline \multirow[t]{3}{*}{ Decision making } & Personal preferences & $\begin{array}{l}\text { Supported: Agree that personal preferences play a role in movements (De VoS, } \\
\text { Dewettinck, \& Buyens, 2008; Ibarra, 2004; Mihal, Sorce, \& Comte, 1984). } \\
\text { Supported: Individuals are prompted to make decisions considering their own values, } \\
\text { beliefs and experiences (Mihal, Sorce, \& Comte, 1984). } \\
\text { Enhanced: Individual career management refers to the process where individuals } \\
\text { analyse the gap between the present and the future, and the relevant actions } \\
\text { associated with it (De Vos, Dewettinck, \& Buyens, 2008). } \\
\text { Enhanced: Some correlation between elements identified in this study with Schein's } \\
\text { (1996) career anchors. }\end{array}$ \\
\hline & Individual factors & $\begin{array}{l}\text { Supported: Importance of the role that individual factors play in career change, } \\
\text { especially the role of skill transferability (Ibarra, 2004; Mihail, 2008). } \\
\text { Enhanced: "age ... may also be an important category" (Ibarra, 2004:17) }\end{array}$ \\
\hline & Process / Method & $\begin{array}{l}\text { Supported: "The choice of a potential solution is influenced by the decision process } \\
\text { one uses" (Mihal, Sorce, \& Comte, 1984, p. 96). } \\
\text { Enhanced: Identification of decision making competencies of knowing why, how and } \\
\text { whom (Mihail, 2008). } \\
\text { Supported: "Many career moves are the result of a haphazard process rather than } \\
\text { careful planning" (Reich \& Kaarst-Brown, 1999:349). }\end{array}$ \\
\hline
\end{tabular}




\begin{tabular}{|c|c|c|}
\hline Job seeking & Job seeking & $\begin{array}{l}\text { Supported: "role of market intermediaries such as headhunters in facilitating career } \\
\text { change" (Ibarra, 2004:5) }\end{array}$ \\
\hline \multirow[t]{5}{*}{$\begin{array}{l}\text { Preparations for a } \\
\text { new career }\end{array}$} & $\begin{array}{l}\text { Expanding work } \\
\text { experience }\end{array}$ & $\begin{array}{l}\text { Supported: Conscious planning by individual to move (Reich \& Kaarst-Brown, 1999) } \\
\text { Supported: Expanding knowledge through job enrichment (De Vos, Dewettinck, \& } \\
\text { Buyens, 2008) or further studies (Ibarra, 2004) } \\
\text { Supported: Importance of meta-ability to create meta-competencies which can be } \\
\text { adapted and applied in various situations (Butcher \& Harvey, 1998) }\end{array}$ \\
\hline & $\begin{array}{l}\text { Supportive roles / } \\
\text { Networking }\end{array}$ & $\begin{array}{l}\text { Supported: "Individuals benefit from support in order to make a successful transition" } \\
\text { (Reich \& Kaarst-Brown, 1999:354) }\end{array}$ \\
\hline & Success & $\begin{array}{l}\text { Enhanced: Breaking down success into subjective and objective successes (Hall \& } \\
\text { Chandler, 2005) }\end{array}$ \\
\hline & Stepping stones & $\begin{array}{l}\text { Supported: "the destination, or new career, in many cases remains undefined and } \\
\text { uncertain for a good portion of the process" (Ibarra, 2004) }\end{array}$ \\
\hline & Interim career & $\begin{array}{l}\text { Supported: Individual's side interests sometimes evolves into more over a period of } \\
\text { time without conscious effort or plans from the individual and thus become a new } \\
\text { career (Ibarra, 2004) }\end{array}$ \\
\hline \multirow[t]{4}{*}{ Coping strategies } & Risk taking & $\begin{array}{l}\text { Supported: “...professionals who moved....without the benefit of ....safety nets to } \\
\text { reduce the risk" (Reich \& Kaarst-Brown, 1999:337). }\end{array}$ \\
\hline & $\begin{array}{l}\text { Apply knowledge } \\
\text { gained }\end{array}$ & $\begin{array}{l}\text { Enhanced: Succession and learning cycles of career transition starting from } \\
\text { "exploration, trail, establishment, and mastery" (Hall \& Chandler, 2005:158). } \\
\text { Supported: "careers are being reconceptualised away from position-oriented job } \\
\text { histories toward a set of experiences and skills accumulated through roles and non- } \\
\text { traditional paths" (Reich \& Kaarst-Brown, 1999:348) }\end{array}$ \\
\hline & Persistence & Supported: "resilience in the face of setbacks" (Martin \& Lekan, 2008:426) \\
\hline & Willing to learn & $\begin{array}{l}\text { Supported: "view their careers as opportunities for experiences in many different } \\
\text { areas" (Reich \& Kaarst-Brown, 1999:348). } \\
\text { Supported: Employees create opportunities for new knowledge and experiences in } \\
\text { order to prepare themselves for future moves (Reich \& Kaarst-Brown, 1999; Martin \& } \\
\text { Lekan, 2008; Peel \& Inkson, 2008). } \\
\text { Supported: The importance of the movement from jobs to experience (Dries, } \\
\text { Pepermans, \& De Kerpel, 2008) }\end{array}$ \\
\hline
\end{tabular}

Source: Author's field notes and literature

In contrast to the above support and enhancements from the literature, a few exceptions in the form of information that does not support my outcomes, were also found. One of these exceptions relate to age as being a trigger for change. Ibarra (2004) concludes that age plays a major role in triggering a transition, especially referring to the mid-life psychological phenomenon. However, this study found that none of the eight participants mentioned or referred to their age during the transition process. In fact, the eight participants are spread between three different generations, hence an assumption can then be made that for this study, age was certainly not a factor to determine career change. Furthermore, it is said that people within the same generation grouping will share a similar "peer personality", and will thus react similarly to certain triggers (Dries, Pepermans, \& De Kerpel, 2008:909). However, this study found that the participants all experienced the same transitioning process regardless of their generation profile.

Another contrast to literature was found, which stated that "in a turbulent environmental context, ..., individuals are less dependent on organizational career arrangements" (Hall \& Chandler, 2005:156). However, this study found that individuals do in fact make use of what was defined as traditional methods. More so, most of the participants utilised established roles and organisational structures within their organisation to expand on their experience. This is also called following an "external career", which is the opposite of an internal career, which refers to an individual's subjective sense of where to go (Suutari \& Taka, 2004:835). Some of the examples of using an external career path include making themselves available for acting in senior positions, being open to changes of job scope where their area of responsibility was increased, and becoming involved in projects in various related and non-related areas of their work.

\section{Discussion}

Substantive theory "is developed from work in a specific area such as a particular type of organisation" (Goulding, 2002:45). A substantive theory does not attempt to explain outside of the immediate field of study. The theory should remain parsimonious, that is, it should not try to generalise with explanations of situations for which there are no data". 
We have applied the four guiding principles as identified by Benecke, Schurink and Roodt (2007) to determine if we have developed a substantive theory and summarised:

- An understanding of the social reality of career transition have been obtained;

- New insight into the phenomenon was obtained in the form of identifying the importance and impact of personal preference throughout the transition process;

- The process of identifying codes, concepts and categories which resulted in the generation of a final core category is explained in detail. "Each concept earns its way into the theory by repeatedly being present in interviews, documents, and observations in one form or the other" (Corbin \& Strauss, 1990:7); and

- The final output consists of a theoretical interpretation of what career transition is through the development of a core category with various sub-categories, which is well defined and relationships are clearly outlined.

Through linking categories and identifying connections between the categories and concepts, a theory about interprofessional career transitions emerged. The core category of personal preferences indicated how the eight participants made sense of their transitions, and in particular, how they moved from point A to point B. All the identified concepts were linked to this core category. In addition, during this research it became evident that career transitions take on many forms. The various participants were all encouraged to transition through different triggers, and similarly reacted differently to their triggers. They all experienced a transition period and had to adapt to their new situation thereafter. Therefore, it is safe to say that they all follow the same sequence. However, it is important to note that although the same sequence was followed, a lot of variations within that sequence lead to a full and descriptive story about career transitions.

\section{The Career transition story}

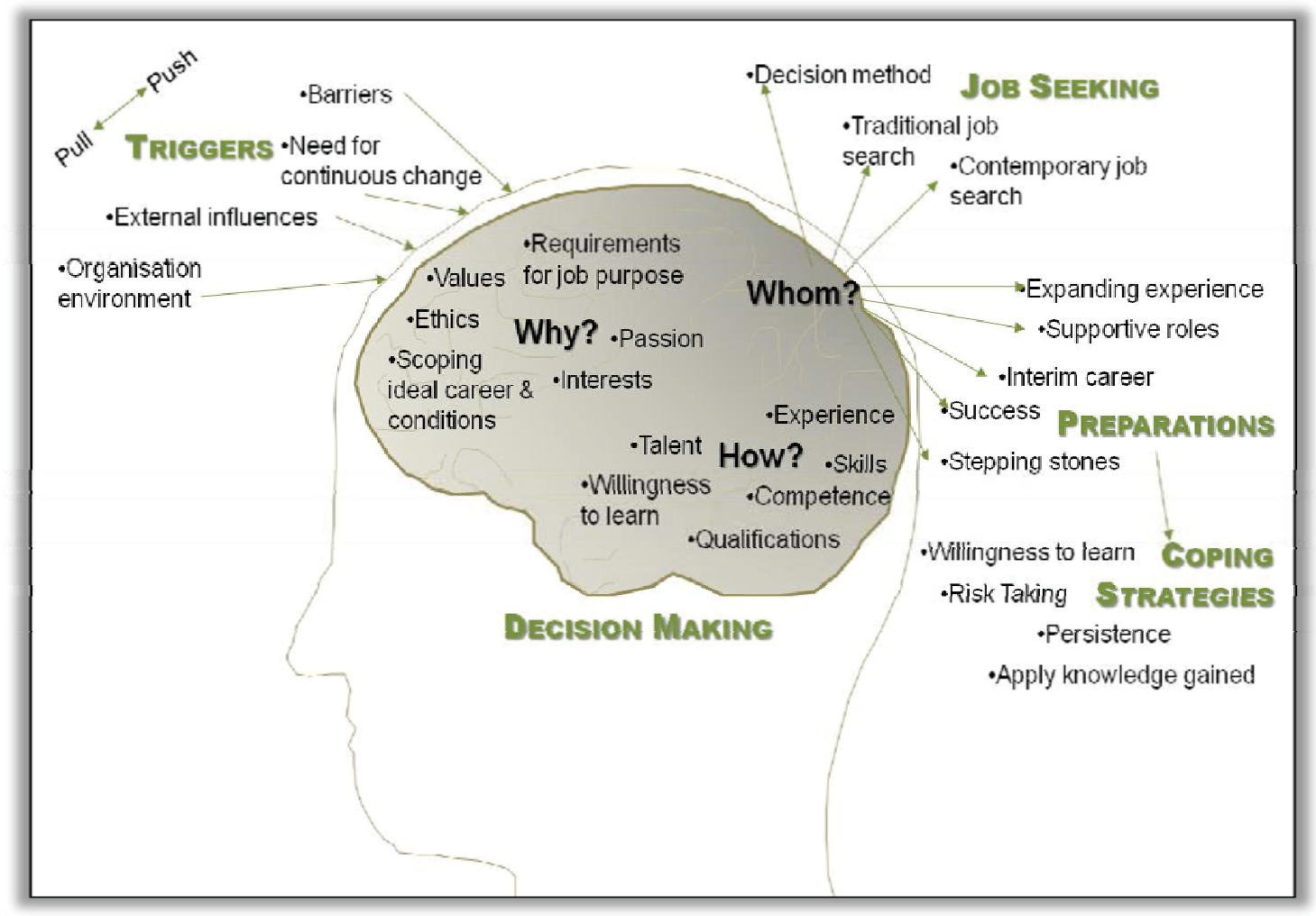

Figure 3: Career transition trajectory based on personal preferences

Source: Authors' Field notes 
This story is explained by presenting Figure 3, which is a schematic picture of how the career transitions of the eight participants culminated. Figure 3 shows that the career transition story is not depicted as a process flow, but rather as an internal process that each individual experiences, indicating both the internal decisions, as well as the external influences that plays a role. Figure 3 also depicts the core category of personal preference as being inside the brain, with all the other categories as either external influences or results from personal preferences.

Individuals should be triggered to make a decision to move or not to move. These triggers differ from person to person, and are based on their personal preferences. For some individuals external influences play a major role, while for others it is an internal process. Therefore, the continuous push-pull factors influence individuals to either move or remain. It is interesting to note that all triggers are reacted upon differently by individuals as barriers for some results in them staying put, while the same barriers can trigger others to make a move to transition.

Once the individual becomes aware of the trigger, a decision is required to move or not to move. During this decision making process, questions such as why, whom and how should be answered in order for the decision to be finalised. Although external elements may influence the decision, the decision itself is an internal process. The internal or external trigger will initiate the "why" question. Therefore, once an individual is triggered, certain elements should be considered. These elements are again based on the personal preference of the individual. For some, their values, interests and passion might be key considerations, while for others they might prefer to identify certain elements of the job, which they need to feel happy. Yet, others might consider all of these elements. Next, the question of "how" should be answered. To answer this question, elements of what is their experience versus what experience is needed to move might be considered. In addition, their skills, competencies, level and type of qualification, as well as their talents and willingness to learn, will also be considered. Again, all of this is an internal process, and is based on the personal preferences of the individual. For example, some individuals might choose to move on to a new job even though they might not have the required experience, while others will opt to first gain experience before they move.

Lastly, as part of the decision process, the question of "how" should be dealt with. The answer to this question results in external actions, as it influences the phases of job seeking and preparation. Within the job seeking phase, the individual should decide on what job seeking method will be applied. Again this depends on the personal preference of the individual, as some will choose to use a traditional job search (curriculum vitae, applying for a job) method, while others will use a more contemporary job search (head hunting, networking, availability to expand experience through any job available) method, and others might use a combination of old and the new methods. The preparation phase is an important phase as this is where individuals set themselves up for the actual movement. Within this phase, individuals might choose to stay with the current organisation, and accept both lateral and vertical movements in order to gain more experience and build more competencies. Others might opt to have an interim or temporary career while they are still studying towards a new role. I call this technique "stepping stones", as the individuals make small movements to better themselves in some way in order to move on to something that they prefer.

Finally, all the decisions and related actions, which stem from their personal preferences, prompt the individual's various coping strategies. One strong coping strategy that was identified is that of their willingness to learn. Other coping strategies that were identified were risk taking, persistence and their ability to apply whatever they learned previously to their new job. The coping strategy that is applied depends on the preference of the individual, and without a coping strategy the individual will not be successful in their new chosen job, as this is their survival kit. It is evident in this story that the golden thread of personal preferences influences every stage of the transition process. Although all of the participants followed the same career transition trajectory, how they reacted to it and how their decisions were influenced was completely based on their personal preferences.

\section{Implications, suggestions and limitations}

A key contribution of the study comprises a theoretical element by providing a career transition story where the category of personal preferences was identified as the key driver for change. Secondly, the study also had two practical contributing elements: 1) it is possible for other want-to-be-transitioners to identify the required steps and thus equip themselves adequately; 2) the outcomes of this study might assist line management to develop training programs and career management programs that will not only benefit the individual during the transitioning process, but the organisation as well, as they now know how individuals experience the transition process.

The results of this study should influence future research in a number of ways. We believe it is necessary to investigate and research how the career transitions of individuals influence both the organisations they move from or into in order to determine how they should react, assist and adapt accordingly in order to remain competitive. In addition, it is 
already stated that the results of this study is not static, as the world of work constantly changes. Although commonalities were identified, which informed the career transition story, certain elements such as the identified triggers and actions that result from decision making will change with time and in line with the world of work. Therefore, a continuous update of these changes and their subsequent impact on the commonalities will be required. Hence, "contextuality and individual differences cannot be left aside when discussing career transitions across countries" (Chudzikowski, et al., 2009:844).

The outcomes of this research are not without limitations. Although the participants were chosen through theoretical sampling and the data in their memoirs and interviews lead to theoretical saturation, some compromises had to be made owing to time and availability on the part of both ourself and the participants. For example, this study began with eight participants who submitted their memoirs, while only three of them submitted their interview notes. This might have limited the point of views.

\section{Summary}

This research began with our general interest on how individuals change careers successfully. This interest shaped a research problem, and in order to answer the problem, the study commenced by compiling a background to the career transition phenomenon. Following an understanding of what information is available, a research design was developed. Owing to the research design, a step-by-step account of how the data was gathered, and what was done with it, was developed. My personal feelings and interpretations of the data were written in a memo format, which also assisted to generate the emerging story line. A career transition fact base was provided, which included all information related to the term career transitioning. A distinction was made between old and new career concepts and types, while a broader perspective focussed on various elements in order to gauge the bigger picture, specifically where it states that career is more than merely a job. This fact base was used to determine how the literature relates to the outcome of the study. Thereafter, the literature findings and the research findings were combined, which informed the final story about career transitioning. In conclusion, we believe that as the reader reads through this article, the research journey and outcomes of the study should be crystal clear, understandable and easy to follow. We also believe that this research study has answered the research problem, and has provided additional insight in relation to the inter-profession career transition phenomenon of working individuals.

\section{References}

Allan, G. (2003). A critique of using grounded theory as a research method. Electronic Journal of Business Research Methods, 2(1), 110.

Atherton, A., \& Elsmore, P. (2007). Structuring qualitative enquiry in management and organization research. Qualitative Research in Organizations and Management: An International Journal, 2(1), 62-77.

Bailey, M. (2003). Uncertainty and Career Transition. Retrieved March 24, 2010, from Career-Tests-Guide: http://www.career-testsguide.com/career-transition.html

Bandow, D., Minsky, B., \& Voss, R. (2007). Reinventing the Future: Investigating Career Transitions from Industry to Academia. Journal of Human Resource Education, 1(1), 23-37.

Baruch, Y. (2004). Transforming careers: from linear to multidirectional career paths. Career Development International, 9(1), 58-73.

Benecke, G., Schurink, W., \& Roodt, G. (2007). Towards a substantive theory of synergy. SA Journal of Human Resource Management, 5(2), 9-19.

Bowen, G. (2005). Preparing a Qualitative Research-Based Dissertation: Lessons Learnt. The Qualitative Report, 10(2), 208-222.

Bridgstock, R. (2011). Skills for creative industries graduate success. Education + Training, 53(1), 9-26.

Brousseau, K., Driver, M., Eneroth, K., \& Larsson, R. (1993). Career pandemonium: Realigning organizations and individuals. Academy of Management Executive, 10(4), 52-66.

Bryant, A., \& Charmaz, K. (2007). Introduction Grounded Theory Research: Methods and Practices. In A. Bryant, \& K. Charmaz, The SAGE Handbook of Grounded Theory (pp. 1-28). Los Angeles: SAGE Publications.

Burden, J., \& Roodt, G. (2007). Grounded Theory and its Application in a Recent Study on Organisational Redesign: Some Reflections and Guidelines. SA Journal of Human Resource Management, 5(3), 11-18.

Butcher, D., \& Harvey, P. (1998). Metqa-abilitly development: a new concept for career management. Career Development International, $3(2), 75-78$.

Carless, D., \& Douglas, K. (2009, Mar). "We haven't got a seat on the bus for you" or "al the seats are mine": narratives and career transition in professional golf. Qualitative Research in Sport and Exercise, 1(1), 51-66.

Carson, K., \& Carson, P. (1997). Career entrenchment: A quit march toward occupational death? Academy of Management Executive, 11(1), $62-75$. 
Charmaz. (2006). Constructing Grounded Theory, A Practical Guide Through Qualitative Analysis. London: SAGE Publications.

Chiovitti, R., \& Piran, N. (2003). Rigour and grounded theory research. Journal of Advanced Nursing, 44(4), 427-435.

Chudzikowski, K., Demel, B., Mayrhofer, W., Briscoe, J., Unite, J., Milikic, B., et al. (2009). Career transitions and their causes: A country-comparative perspective. Journal of Occupational Psychology, 82, 825-849.

Clarke, M. (2009). Plodders, pragmatsts, visionaries and opportunists: career patterns and employabilitliy. Career Development International, 14(1), 8-28.

Corbin, J., \& Strauss, A. (1990). Grounded Theory Research: Procedures, Canons, and Evaluative Criteria. Qualitative Sociology, 13(1), 3-21.

Corbin, J., \& Strauss, A. (2008). Basics of Qualitative Research. Techniques and Procedures for Dveloping Grounded Theory (3e ed.). Los Angeles: SAGE Publications.

De Briun, G., \& Buchner, M. (2010). Factor and item response theory analysis of the Protean and Boundaryless Career Attitude Scales. SA Journal of Industrial Psychology, 36(2).

De Vos, A., Dewettinck, K., \& Buyens, D. (2008). To move or not to move? The relationship between career management and preferred career moves. Employee Relations, 30(2), 156-175.

Doer, D. (1995). Coping with the Emotions of Job Transition: A Model for Presentation to Clients. Journal of Career Development, 22(2), 101-107.

Donahue, R. (2006). Person-environment congruence in relation to career change and career persistence. Journal of Vocational Behaviour, 68, 504-515.

Dries, N., Pepermans, R., \& De Kerpel, E. (2008). Exploring four generations' beliefs about career. Journal of Managerial Psychology, 23(8), 907-928

Duberley, J., Mallon, M., \& Cohen, L. (2006). Exploring career transitions: accounting for structure and agency. Personnel Review, 35(3), 281-296.

El-Sabaa, S. (2001). The skills and career path of an effective project manager. International Journal of Project Management, $19,1-7$.

Foot, D., \& Vene, R. (1990, Dec). Population, Pyramids and Promotional Prospects. Canadian Public Policy / Analyse de Politiques, 16(4), 387-398.

Ford, E. (2008, Feb 14). How to change career. Retrieved Oct 14, 2009, from Times Online: http://business.timesonline.co.uk/tol/business/career_and)jobs/graduate_management/...

Frank, W. (1996). The 11 Steps in Career Transition. Retrieved OCt 14, 2009, from Career Lab: http://www.careerlab.com/art 11steps.htm

Gerber, M., Wittekind, A., Grote, G., Conway, N., \& Guest, D. (2009). Generalizability of career orientations: A comparative study in Switzerland and Great Britain. Journal of Occupational and Organizational Psychology, 82, 779-801.

Glaser. (1978). Theoretical Sensitivity. Mill Valey: Sociology Press.

Glaser. (2002). Conceptualization: On Theory and Theorizing Using Grounded Theory. International Journal of Qualitative Methods, $1(2), 1-31$.

Glaser, B. (1992). Basics of grounded theory analysis: Emergence vs. forcing. Mill Valley, CA: Sociology Press.

Glaser, B., \& Strauss, A. (1967). The Discovery of Grounded Theory. Chicago: Aldine.

Goulding, C. (1999, June). Grounded Theory: some reflections on paradigm, procedures and misconceptions. University of Wolverhampton.

Goulding, C. (2002). Grounded Theory. A Practical Guide for Management, Business and Market Researchers. London: SAGE Publications Ltd.

Hall, D. (1996). Protean Careers of the 21st Century. Academy of Management Executive, 10(4), 8-16.

Hall, D., \& Chandler, D. (2005). Psychological success: When the career is a a calling. Journal of Organizational Behavior, 26(2), 155176.

Ibarra, H. (2002, Dec). How to Stay Stuck in the Wrong Career. Harvard Business Review, 40-47.

Ibarra, H. (2004, 12 13). Career Transition and Change. Retrieved 12 18, 2012, from Insead: http://www.insead.edu/facultyresearch/research/doc.cfm?did=1477

Kelly, A., Brannick, T., Hulpke, J., Levine, J., \& To, M. (2003). Linking organisational training and development practices with new forms of career structure: a cross-national exploration. Journal of European Industrial Training, 27(2/3/4), 160-168.

Kraus, S. (2005). Research Paradigms and Meaning Making: A Primer. The Qualitative Report, 10(4), 758-770.

LaRossa, R. (2005, November). Grounded Theory MEthods and Qualitative Family Research. Journal of Marriage and Family, 67, 837857.

Levchuck, C. (2009). How to Chanage Careers Part 1: Is a Career Change Right for You? Retrieved Oct 16, 2009 , from Yahoo Hot Jobs: http://hotjobs.yahoo/careerchange/How_to_Change_Careers_Part_1_Is_a_Career...

Lichtenstein, B., \& Mendenhall, M. (2002). Non-linearity and response-ability: Emergent order in 21st-centurary careers. Human Relations, 55(1), 5-32.

Locke, K. (2001). Grounded Theory in Management Research. London: SAGE Publications.

Louis, M. (1980, Jul). Career Transitions: Varieties and Commonalities. The Academy of Management Review, 5(3), 329-340.

Louis, M. (1982). Managing Career Transition: A Missing Link in Career Development. Organizational Dynamics, 10(4), 68-77.

Martin, H., \& Lekan, D. (2008). Individual differences in outplacement success. Career Development International, 13(5), 425-439. 
Mayrhofer, W., Meyer, M., Schiffinger, M., \& Schmidt, A. (2008). The influence of family responsibilities, career fields and gender on career success. Journal of Managerial Psychology, 23(3), 292-323.

McDonald, P., Brown, K., \& Bradley, L. (2005). Have traditional career paths given way to protean ones? Evidence from senior managers in the Australian public sector. Career Development International, 10(2), 109-129.

Mihail, D. (2008). Grauates' career orientations and strategies in corporate Greece. Personnel Review, 37(4), 393-411.

Mihal, W., Sorce, P., \& Comte, T. (1984). A Process Model of Individual Career Decision Making. The Academy of Management Review, 9(1), 95-103.

Mills, J., Bonner, A., \& Francis, K. (2006, April). The Development of Contructivist Grounded Theory. Retrieved December 19, 2011, from http://www.ualberta.ca/ iiqm/backissues/5_1/html/mills.htm

Moen, P. (2005, Jun). Beyond the Career Mystique: "Time in," "Time Out," and "Second Acts". Sociological Forum, 20(2), $189-208$.

Morse, J., Stern, P., Corbin, J., Bowers, B., Charmaz, K., \& Clarke, A. (2009). Developing Grounded Theory. The Second Generation. Walnut Creek, CA: Left Coast Press Inc.

Murtagh, N., Lopes, P., \& Lyons, E. (2007). Waht makes a career barrier a barrier? Industrial and Commerical Training, 39(6), $332-339$.

Pandit, N. (1996). The Creation of Theory: A Recent Application of the Grounded Theory Method. The Qualitative Report, 2(4).

Peel, S., \& Inkson, K. (2008). Contracting and careers: choosing between self and organizational employment. Career Development International, 9(6), 512-558.

Pidgeon, N., \& Henwood, K. (1997). Using grounded theory in psychological research. In N. Hayes, Doing Qualitative Analysis in Psychology (pp. 245-273). Taylor \& Francis Inc.

Reetley, A. (2008, Nov 12). A literature review on grounded theory. Retrieved Apr 12, 2011, from UJDigiSpace: http://ujdigispace.uj.ac.za:8080/dgspace/handle/102/1612

Reich, B., \& Kaarst-Brown, M. (1999). "Seeding the Line": Understanding the Transition form IT to Non-IT Careers. MIS Quarterly, 23(3), 337-364.

Rettie, R., Robinson, H., Radke, A., \& Ye, X. (2008). CAQDAS: a supplementary tool for qualitative market research. Qualitative Market Research: An International Journal, 11(4), 76-88.

Rhodes, S., \& Doering, M. (1983, Oct). An Integrated Model of Career Change. The Academy of Management Review, 8(4), 631-639.

Robbins, S. (2001). Organizational Behavior. UpperSaddle River, New Jersey: Prentice Hall International, Inc.

Sargent, L., \& Domberger, S. (2007). Exploring the development of a protean career orientation: values and image violation. Career Development International, 12(6), 545-564.

Saunders, M., Lewis, P., \& Thornhill, A. (2003). Research Methods for Business Students (3 ed.). England: Pearson Educational Limited.

Schein, E. (1984, Jan). Culture as an Environmental Cotext for Careers. Journal of Occupational Behaviour, 5(1), 71-81.

Schein, E. (1996). Career anchors revisited: Implications for career development in the 21st century. Academy of Management Executive, 00(0), 80-86.

Schlossberg, N. (1981). A model for analysing human adaptation to transition. The Counseling Psychologist, 9, 2-18.

Suddaby, R. (2006). From the Editors: What Grounded Theory is Not. Academy of Management Journal, 49(4), 633-642.

Suutari, V., \& Taka, M. (2004). Career anchors of managers with global careeers. Journal of Management Development, 23(9), 833-847.

Teixeira, M., \& Gomes, W. (2000). Autonomous Career Change Among Professionals: An Emperical Phenomenological Study. Journal of Phenomenological Psychology, 31(1), 78-96.

Terre Blanche, M., \& Durrheim, K. (1999). Research in Practice. Applied Methods for the Social Science. Cape Town: University of Cape Town Press (Pty) Ltd.

Thorne, S. (2000). Data analysis in qualitative research. Evidence-Based Nursing, 3, 68-70.

Willig, C. (2001). Introducting Qualitative Research in Psychology. Buckinham - Philadelphia: Open University Press.

Willig, C. (2008). Introducing Qualitative Research in Psychology (2nd Edition ed.). New York: Open University Press McGraw-Hill Education.

Woodd, M. (2000). The move towards a different career pattern: are women better prepared than men for a modern career? Career Development International, 5(2), 99-105.

Yin, R. (1989). Case Study research: Design and Mehtods. London: SAGE Publications. 